\title{
MODIFICATION OF DELTA FOR CHOOSER OPTIONS
}

Marek Durica ${ }^{1}$

\begin{abstract}
Correctly used financial derivatives can help investors increase their expected returns and minimize their exposure to risk. To ensure the specific needs of investors, a large number of different types of nonstandard exotic options is used. Chooser option is one of them. It is an option that gives its holder the right to choose at some predetermined future time whether the option will be a standard call or put with predetermined strike price and maturity time. Although the chooser options are more expensive than standard European-style options, in many cases they are a more suitable instrument for investors in hedging their portfolio value. For an effective use of the chooser option as a hedging instrument, it is necessary to check the values of the Greek parameters delta and gamma for the options. Especially, if the value of the parameter gamma is too large, hedging of the portfolio value using only parameter delta is insufficient and brings high transaction costs because the portfolio has to be reviewed relatively often. Therefore, in this article, a modification of delta-hedging as well as using the value of parameter gamma is suggested. Error of the delta modification is analyzed and compared with the error of widely used parameter delta. Typical patterns for the modified hedging parameter variation with various time to choose time for chooser options are also presented in this article.
\end{abstract}

JEL Classification Numbers: C00, G13, G23, DOI: http://dx.doi.org/10.12955/cbup.v3.593

Keywords: Chooser, option, delta, gamma, hedging

\section{Introduction}

The development of the financial market and growing uncertainty of its participants are the main motivation for investors to look for new financial instruments. The level of investment risk is increasing simultaneously; therefore, everyone operating in financial markets has to react to market changes and to correct their investment strategy in time. For this reason, investors are looking for new investment possibilities that could adapt to the changing situation in the market while generating income from the investment.

Correctly used derivatives can help investors increase their expected returns and minimize their exposure to risk. Since the first time options were traded in 1973, the volumes of their trade have risen rapidly all over the world.

Standard types of options are traded actively, but new types of options bring possibilities for investors in hedging their investment portfolios. Over the last decades, the transaction size of exotic options in the financial markets has expanded. A large variety of these instruments is available to investors. Exotic options are a general name to derivative securities that have more complex cash-flow structures than standard put and call options. The main motivation for trading exotic options is that they allow a much more precise view on future market behavior than those offered by "plain vanilla" options. These options are usually traded over the counter and are marketed by sophisticated corporate investors or hedge funds. They have almost unlimited possibilities and can be adapted to the specific needs of any investor. These options are playing a significant hedging role because they meet the needs of hedgers in cost effective ways. Exotic options are usually less expensive and more efficient than standard instruments. Exotic options can be used as attractive investments and trading opportunities.

\section{Theoretical background of chooser options}

An option is an instrument giving its owner the right but not the obligation to buy or sell something at a fixed price specified in advance. There are two types of options. A call option gives the holder the right to buy the underlying asset at the strike price before time expiration. The writer of the option has

\footnotetext{
${ }^{1}$ RNDr. Marek Ďurica, PhD. University of Žilina, Faculty of Operation and Economics of Transport and Communications, Department of Quantitative Methods and Economic Informatics, Slovak Republic, marek.durica@fpedas.uniza.sk
} 
the obligation to sell the underlying asset if the buyer of the call option decides to exercise his right to buy. A put option gives the holder the right to sell the underlying asset at the strike price before time expiration. The writer of the put option has the obligation to buy the underlying asset at the strike price if the seller decides to exercise his right to sell. Strike price or exercise price is the price at which the option holder has the right to buy or to sell the underlying asset.

As Hull (2012) wrote, the style of an option specifies when that option is exercisable. There may be two different styles of options. An American style option may be exercised at any time prior to its expiration. European style option may be exercised only during a specified period before the option expires. Usually such an option is exercised on its day of expiration.

All mentioned aspects of the plain options are the same for the exotic options. Exotic options may have uncertain exercise prices, expiration time, and several underlying assets. Exotic options are mainly over the counter instruments.

A chooser option is part of the exotic option family. It is an option on options and is one of pathdependent options. A standard chooser option gives its holder the right to decide at some pre-specified time whether the option will finally be a put or a call. This option is sometimes called "as-you-like" option and was introduced by Rubinstein (1991a; 1991b). The strike prices of the call and put option may be the same, but it is not necessary. If the strikes are the same, the chooser option is named a simple chooser option. When the strikes or even expiry dates are not the same, this option is referred to as a complex chooser option by De Weert (2008).

A chooser option is suitable for investors who expect strong volatility of the underlying asset but are not certain about direction of the change. According to Rubinstein (1991a; 1991b) and Faseruk, Deacon, \& Strong (2004), holding a chooser option is similar to holding a straddle strategy, which consists of a put and call options with the same strike price. But the chooser holder does not have to pay for both options. He is flexible to decide which option to buy later. A straddle holder has to pay for both options immediately. For this reason, the chooser options are less expensive than straddles.

\section{Basic principles of option pricing}

Many scientific studies are devoted to analyzing different methods of options pricing because the valuation of options is very complex.

The most popular valuation model for options is the Black-Scholes-Merton model introduced by Black \& Scholes (1973) and Merton (1973). The model is based on the theory that markets are arbitrage-free and assumes that the price of the underlying asset is characterized by a Geometric Brownian motion. An analytic solution of this model for pricing European options is commonly used.

Monte Carlo simulation is a numerical method for pricing options. This technique was first used by Boyle (1977). For the option pricing, we need to find the expected value of the price of the underlying asset on the expiration date. Since the price is a random variable, one possible way of finding its expected value is by simulation. This model can be adapted to pricing almost any type of option as stated by Boyle, Broadie \& Glassermann (1997).

Another technique for pricing options is the binomial tree model, which was first used by Cox, Ross, \& Rubinstein (1979). It is a simplification of the Black-Scholes-Merton approach as it considers the fluctuation of the price of the underlying asset in discrete time. This model is typically used to determine the price of European and American options.

As Hull \& White (1990) described, another alternative method for options pricing is a finite difference method, which is based on the Black-Scholes-Merton model. This numerical method consists of a reduction of the field of solution to a finite number of points, and the replacement of partial 
derivations in Black-Scholes-Merton model by given differences. This approach leads to an equation or to a system of equations whose solution is the numerical estimate of the option price. This numerical method could be very useful for the option pricing, especially for more complex types of exotic options whose price have to be set numerically as written by Švábová (2014).

\section{Black-Scholes-Merton model}

It is not easy to determine the right price of an option in practice. A huge number of pricing models was generated to solve this problem. The Black-Scholes-Merton model and the binomial model (Cox et al., 1979) are the two most used pricing models. The Black-Scholes-Merton model is used to calculate a theoretical price of the option using the five key factors of an option's price - underlying stock price, strike price, volatility, time to expiration, and risk-free interest rate. Some assumptions were added to derive Black-Scholes-Merton model: there are no transaction costs; there are no dividends during the life of the option; there are no riskless arbitrage opportunities; security trading is continuous; the stock price follows geometric Brownian process with constant mean and standard deviation; and, the risk-free rate of interest is constant and the same for all maturities.

Although Black-Scholes-Merton model was derived for valuing European call and put options on a non-dividend-paying stock, this model can be extended to deal with European call and put options on dividend-paying stocks, American options, or options with different underlying assets:

$$
\begin{gathered}
c_{B S M}(S, X, T)=S e^{-q T} N\left(d_{1}\right)-X e^{-r T} N\left(d_{2}\right), \\
p_{B S M}(S, X, T)=X e^{-r T} N\left(-d_{2}\right)-S e^{-q T} N\left(-d_{1}\right), \\
d_{1}=\frac{\ln (S / X)+\left(r-q+\sigma^{2} / 2\right) T}{\sigma \sqrt{T}}, d_{2}=d_{1}-\sigma \sqrt{T}
\end{gathered}
$$

where:

$c_{B S M}$ or $p_{B S M}$ is a value of a European call or put option calculated by Black-Scholes-Merton model;

$S$ is the underlying stock price;

$X$ is exercise price;

$T$ is time to maturity;

$r$ is risk-free interest rate;

$q$ is dividend yield;

$\sigma$ is volatility of stock price;

$N$ is the cumulative normal distribution function.

\section{Chooser options pricing}

As mentioned earlier, a chooser option gives an investor the right to choose, at a pre-specified time, whether the option will be a call or a put. Once this choice was made, the option stays as a call or a put until the time of maturity. At this moment, the chooser option has the same payoff as the straddle strategy, but it will be cheaper. The reason for the lower price is that the straddle always has a positive payoff and the chooser can end up costing the investment.

An analytical solution for pricing the chooser options is possible because if the options underlying the chooser are both European and have the same strike price, put-call parity can be used to provide a valuation formula. This was proven by Rubinstein (1991a; 1991b). 
The value of the simple chooser option at the choice time $t$ is

$$
\max \left[c_{B S M}\left(S_{t}, X, T-t\right), p_{B S M}\left(S_{t}, X, T-t\right)\right],
$$

where $c_{B S M}$ is the value of the call option underlying this option, and $p_{B S M}$ is the value of the call option underlying this option. As demonstrated in details by Whaley (2006) and Ďurica \& Švábová (2014), the value of a chooser option is

$$
\begin{gathered}
c_{\text {chooser }}(S, X, t, T)= \\
=S e^{-q T} N\left(d_{1}\right)-X e^{-r T} N\left(d_{2}\right)-S e^{-q T} N\left(-d_{1}^{*}\right)+X e^{-r T} N\left(-d_{2}^{*}\right),
\end{gathered}
$$

where

$$
\begin{gathered}
d_{1}=\frac{\ln (S / X)+\left(r-q+\sigma^{2} / 2\right) T}{\sigma \sqrt{T}}, d_{2}=d_{1}-\sigma \sqrt{T}, \\
d_{1}^{*}=\frac{\ln (S / X)+(r-q) T+\left(\sigma^{2} / 2\right) t}{\sigma \sqrt{t}}, d_{2}^{*}=d_{1}^{*}-\sigma \sqrt{t} .
\end{gathered}
$$

If $t=T$, then the chooser option is the same as a European-style straddle, i.e. equals to the sum of the values of an European call and put option with strike price $X$ and maturity time $T$.

\section{The delta and gamma of a chooser option}

The delta of a chooser option is the rate of change in the value of the chooser option with respect to the change in the underlying asset price. This change can be calculated using the partial derivative of a chooser option price with respect to the variable $S$. Therefore, the delta of a chooser option is

$$
\Delta_{\text {chooser }}=\frac{\partial c_{\text {chooser }}}{\partial S}=e^{-q T} N\left(d_{1}\right)+e^{-q T}\left[N\left(d_{1}^{*}\right)-1\right]
$$

where $d_{1}$ is defined in equation (3) and $d_{1}^{*}$ in equation (7).

The gamma is the rate of change of delta with respect to the price of the underlying asset. Therefore, gamma can be calculated as a derivative of delta with respect to the price of the underlying asset. Then, the gamma of a chooser options is

$$
\Gamma_{\text {chooser }}=\frac{\partial^{2} c_{\text {chooser }}}{\partial S^{2}}=\frac{\partial \Delta_{\text {chooser }}}{\partial S}=\frac{e^{-q T} N^{\prime}\left(d_{1}\right)}{S \sigma \sqrt{T}}+\frac{e^{-q T} N^{\prime}\left(d_{1}^{*}\right)}{S \sigma \sqrt{t}},
$$

where $d_{1}$ is defined in equation (3) and $d_{1}^{*}$ in equation (7).

These expressions for delta and gamma for chooser options were derived by Ďurica \& Švábová (2014).

\section{Modification of the delta for chooser options}

For larger changes in the spot underlying asset price (especially in the case where the price of that asset is near chooser option strike price), reliability of parameter delta is limited. And, for a more accurate estimate of the change in the price of the option, using a parameter gamma is necessary. Using the properties of the Taylor expansion, we obtain the expected change in chooser option as the sum of 


$$
\Delta+\frac{1}{2} \Gamma
$$

To use this parameter in order to ensure the short position in the chooser option, holding $\Delta+\frac{1}{2} \Gamma$ at the long position in the underlying asset at each point in time is required. Similarly, to ensure the long position in the chooser option, holding $\Delta+\frac{1}{2} \Gamma$ at the short position in the asset at each time is required. This modification was also studied for futures options by Ďurica \& Švábová (2013).

Using the parameter $\Delta+\frac{1}{2} \Gamma$ to estimate the change in the chooser option price is significantly more accurate than using of parameter delta as shown in Figure 1. This figure illustrates the error between the real change in chooser option price and estimated change, using delta and the error between the real change in the chooser option (dashed line) and change calculated using parameter $\Delta+\frac{1}{2} \Gamma$ (solid line). These errors are calculated for futures call option with the time to choose of 1 year, 90 days, 30 days and 1 day. The time duration between time to choose and time to maturity is 180 days. Strike price of this chooser option is $\$ 80$; risk-free interest rate is $5 \%$; volatility is $29 \%$; and, dividend-yield is $4 \%$.

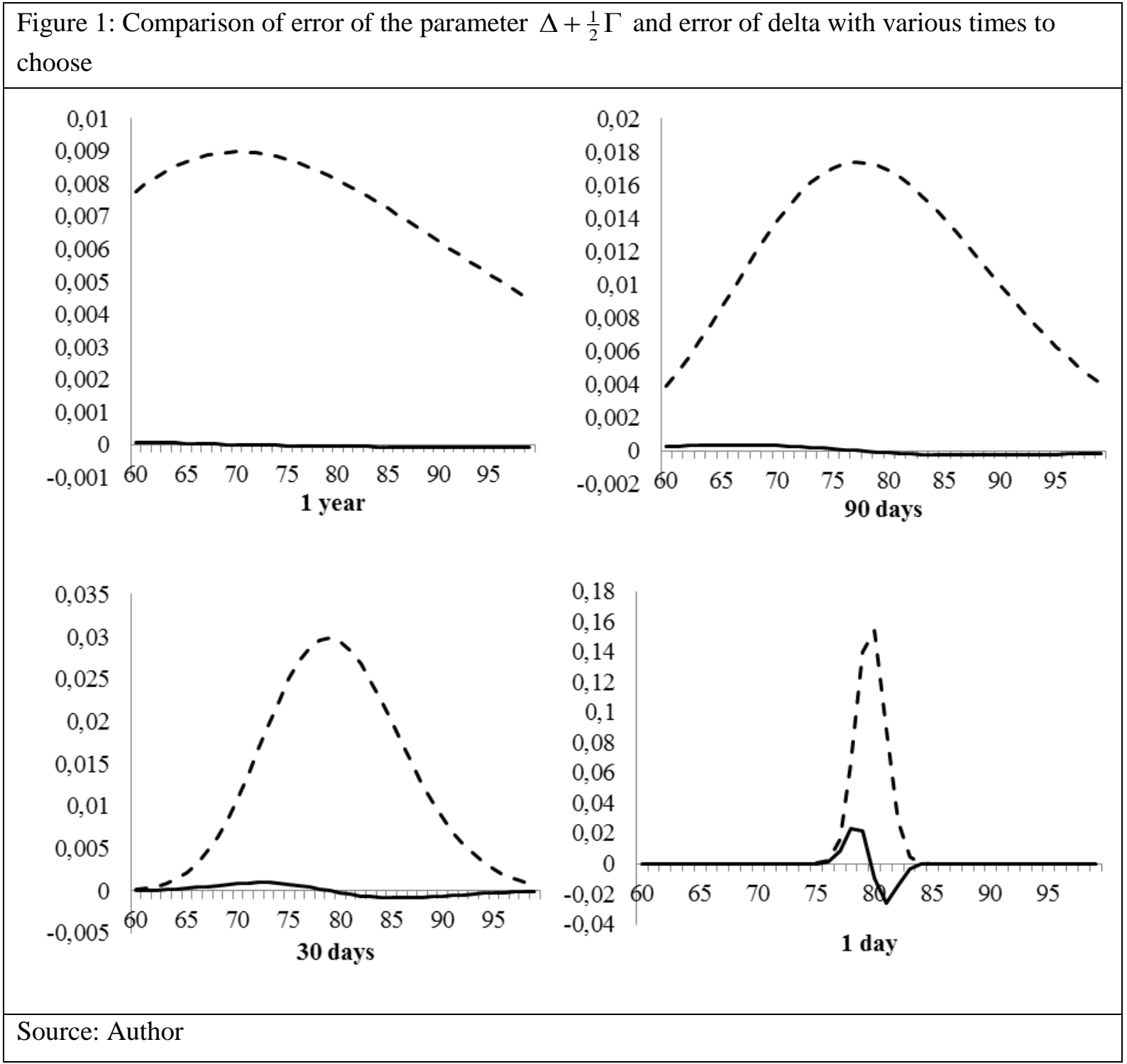


The parameter $\Delta+\frac{1}{2} \Gamma$ is more precise than the delta parameter as shown in Figure 1. The error of parameter $\Delta+\frac{1}{2} \Gamma$ is also smaller than the error of parameter delta for all times to choose. The error of parameter $\Delta+\frac{1}{2} \Gamma$ increases as time to choose decreases. This error could be reduced using more members of the Taylor expansion. But, this error is almost insignificant in real options trading, so this is just a theoretical and mathematical consideration.

\section{Conclusion}

Previous analysis shows that the sensitivity of a chooser option price to changes in the underlying asset price is evident, especially for options with underlying asset price close to the strike price. Furthermore, it is clear that the sensitivity increases as the time to maturity decreases.

Gamma of a chooser option with the underlying asset price far from the strike price is almost zero. Therefore, a static delta-hedging is sufficient in this case. It is sufficient to create a delta-neutral portfolio and to review this portfolio only in the case of major changes in the underlying asset price. Whenever the underlying asset price gets closer to the strike price of the option, the parameter gamma can take on large values, especially for time close to the choosing time. In this case, it is necessary to use dynamic delta-hedging and review the portfolio more often, which may incur high transaction costs. Then, it is appropriate to use the suggested modified hedging parameter, which better estimates the changes in chooser option price with respect to the change in the underlying asset price. So that the static hedging based on this parameter is sufficient. This could be the way for the investors to reduce the transaction costs related to hedging of their investment portfolio value, by using the financial derivatives - especially chooser options.

\section{Acknowledgements}

This article was written in response to the project co-funded by the EU called "The quality of education and human resources development as pillars of a knowledge society at the Faculty PEDAS, ITMS 26110230083."

\section{References}

Black, F., \& Scholes, M. (1973). The Pricing of Options and Corporate Liabilities. Journal of Political Economy, 81(3), $637-654$.

Boyle, P. P. (1977). Options: A Monte Carlo Approach. Journal of Financial Economics, 4, 323-338.

Boyle, P. P., Broadie. M., \& Glassermann, P. (1997). Monte Carlo Methods for Security Pricing. Journal of Economic Dynamics and Control, 21, 1267-1322.

Cox, J. C., Ross, S. A., \& Rubinstein, M. (1979). Option Pricing: A Simplified Approach. Journal of Financial Economics, 7, $229-264$.

De Weert, F. (2008). Exotic Options Trading. England: John Wiley \& Sons.

Durica, M., \& Švábová, L. (2013). An improvement of the delta-hedging of the futures options. International scientific conference FMFFI 2013 Full Paper Proceedings, 140-148.

Ďurica, M., \& Švábová, L. (2014). Delta and Gamma for Chooser Options. International Scientific Conference AMSE 2014 Full Paper Proceedings, 75-84. doi: 10.15611/amse.2014.17.08

Faseruk, A., Deacon, C., \& Strong, R. (2004). Suggested Refinements to Courses on Derivatives: Presentation of Valuation Equations, Pay Off Diagrams and Managerial Application for Second Generation Options. Journal of Financial Management and Analysis, 17(1), 62-76.

Hull, J. C., \& White, A. (1990). Valuing Derivative Securities Using the Explicit Finite Difference Method. Journal of Financial and Quantitative Analysis, 25, 87-100.

Hull, J. C. (2012). Options, Futures, and Other Derivatives (8th ed.). Pearson Education, England.

Merton, R. C. (1973). Theory of Rational Option Pricing. The Bell Journal of Economics and Management Science, 4(1), 141-183.

Rubinstein, M. (1991a). Pay now, choose later. Risk, 4(2), 44-47.

Rubinstein, M. (1991b). Options for the undecided. Risk, 4(4), 70-73.

Švábová, L. (2014). Option pricing using Finite Difference Method. International Scientific Conference BT 2014 Full Papers Proceedings.

Whaley, R. E. (2006). Derivatives, Markets, Valuation and Risk Management. New Jersey: John Wiley \& Sons. 